\title{
Bond between Smooth Prestressing Wires and Concrete: Finite Element Model and Transfer Length Analysis for Pretensioned Concrete Crossties
}

\author{
Hailing $\mathrm{Yu}^{1}$ and David Y. Jeong ${ }^{2}$ \\ ${ }^{1}$ Structures and Dynamics Division, Volpe National Transportation Systems Center, 55 \\ Broadway, Cambridge, MA 02142; PH (617) 494-2554; email: hailing.yu@dot.gov \\ ${ }^{2}$ Structures and Dynamics Division, Volpe National Transportation Systems Center, 55 \\ Broadway, Cambridge, MA 02142; PH (617) 494-3654; email: david.jeong@ dot.gov
}

\begin{abstract}
Pretensioned concrete ties are increasingly employed in railroad high speed and heavy haul applications. The bond between prestressing wires or strands and concrete plays an important role in determining the transfer length of pretensioned concrete members, but little research was done to characterize the transfer length in terms of steel reinforcement and concrete factors for railroad concrete ties. Federal Railroad Administration is sponsoring a comprehensive test program at Kansas State University (KSU) aimed at quantitatively correlating prestressing steel and concrete variables with the transfer length of pretensioned concrete crossties, and Volpe Center has been applying the data obtained in the KSU test program to develop bond models that can be used in transfer length prediction and failure analysis of concrete ties.

This paper describes finite element (FE) model development related to the smooth prestressing wire whose dominant bonding mechanisms with concrete are chemical adhesion and friction. The commercial FE software Abaqus is employed, and the steel-concrete interface is discretized with cohesive elements. A user bond model is developed within the elastoplastic framework and implemented for axisymmetric and 3D cohesive elements. The bond model defines constitutive relations in terms of normal and shear stresses vs. interfacial dilation and slips. The bond behavior is initially linear elastic, followed by adhesion and friction that are governed by a yield function and a plastic flow rule specific for the smooth wireconcrete interface. The main bond material parameters are normal and shear elastic stiffness, initial adhesive strength, plastic slip at which adhesion first breaks completely, and coefficient of friction. Except for the coefficient of friction, which is determined with reference to the open literature, the bond parameters are calibrated from untensioned pullout tests and pretensioned prism tests conducted at KSU. The calibrated bond parameters exhibit a dependence on the nominal compressive strength of concrete at the time of pretension release. Because considerable concrete creeping has been observed in the periods between pretension release and concrete strain measurement in the test program, an additional concrete material parameter, basic creep compliance, can be calculated and applied to adjust the concrete surface strain data. The user bond model is then validated with transfer length data measured on actual concrete crossties made with a smooth prestressing wire in a tie manufacturing plant.
\end{abstract}




\section{INTRODUCTION}

Ties are an integral part of a railroad track system which also includes rails, rail pads, insulators, fasteners and ballast. The main functions of railroad ties include anchoring rails against lateral and longitudinal movements, transferring rail forces to the ballast bed, maintaining track gauge and rail inclination, and insulating rails electrically. Concrete ties can be engineered to meet specific service requirements and add overall stability and performance to a railroad track structure. Concrete ties were estimated to last twice as long as timber ties, meaning lowered life cycle costs despite a higher initial cost. These desirable qualities led to great interest and the first major installation of prestressed concrete ties in North America in 1966 (Hanna, 1979). It is estimated that tens of millions of concrete ties have been installed in the U.S. freight and passenger rail systems. Nevertheless, concrete ties account for only a small percentage of ties in track in North America, as unresolved performance issues have prevented concrete ties from more widespread use.

A study on behalf of Railway Tie Association examined approximately 29 million concrete ties installed since the 1970's and found a failure rate of 7.9-9.2\% based on concrete crosstie performance data collected from the freight and passenger rail industry in U.S. and Canada (ZETA-TECH, 2010). Of the 7.4 million concrete ties installed in the 1970's and 1980's, the failure rate was even higher at 22.2\%. The common failure modes of concrete ties include chemical degradation, center binding, rail seat cracking, rail seat deterioration, splitting/bursting cracks, shoulder/fastener wear or fatigue, freeze-thaw cracking, etc. A more recent survey further ranked the various failure modes according to how critical they were viewed by infrastructure owners and operators, researchers and tie manufacturers (Van Dyk et al., 2012).

Concrete ties are made by casting concrete around pretensioned steel wires or strands. As the concrete cures, it bonds with the steel reinforcements. When the tension at the steel ends is released, the prestress is transferred to the concrete member via bond. This results in an initial compressive stress state in concrete that can compensate for its low strength in tension. There exists a transfer length over which the prestress develops into the full design amount. If the transfer length extends to the rails seat area, which bears the dynamic vehicle-track loads, the precompression in concrete may be underdeveloped in this area and thus insufficient to counter the tensile stresses resulting from the dynamic loads, and concrete tie failure such as rail seat cracking may occur. Therefore, transfer length is an important quality control parameter to be monitored in the concrete tie manufacturing process.

Transfer length can be affected by various factors such as surface indents and surface conditions of the steel reinforcement and strength of the concrete, but little research was done to quantitatively characterize these effects for concrete ties. Federal Railroad Administration is currently sponsoring a comprehensive test program at Kansas State University (KSU) to quantitatively correlate prestressing steel and concrete variables with the transfer length of pretensioned concrete crossties. The authors of this paper have been developing detailed concrete tie models for railroad track analyses but often found the available interface material models to be inadequate (Yu et al., 2011, Yu and Jeong, 2012). The KSU test program has 
provided much needed data to develop finite element (FE) bond models for the steel reinforcement-concrete interfaces. The bond models will be an essential component of entire concrete tie models useful for predicting not only transfer lengths but also failure modes related to prestresses in concrete.

The elastoplastic framework is well established for modeling bond in reinforced concrete applications (e.g., Cox and Herrmann, 1998) and similarly adopted in this study to develop FE models for bond in concrete ties. A main objective of the KSU project has been to examine the proposition that indented wires or strands can improve the bonding quality with concrete and thus reduce the transfer length. The bond models we are developing are intended to be specific to reinforcement indent. As a first step, an elastoplastic bond model for the smooth prestressing wire, whose dominant bonding mechanisms with concrete are chemical adhesion and friction, is developed and presented in this paper.

The organization of this paper is as follows. First an overview of the KSU test program is given. Next the elastoplastic FE modeling framework for bond is presented, and yield function and flow rule specific for the interface of the smooth prestressing wire are defined. The bond model is then calibrated and validated with test data obtained in the KSU test program. Finally conclusions are drawn from this study, and future work on modeling the bond of indented wires or strands is discussed.

\section{OVERVIEW OF TEST PROGRAM}

The prestressing reinforcements used in the railroad concrete tie industry include $5.32 \mathrm{~mm}$ diameter, low relaxation steel wires, and 3/8 inch or 5/16 inch diameter, low relaxation steel strands in three- or seven-wire configuration. To gain a better understanding of how these reinforcements bond with concrete, the KSU research team examined a total of 12 prestressing wires (1 smooth, 2 with spiral indents, 1 with diamond indents, 6 with chevron indents and 2 with dot indents) and 6 prestressing strands ( 1 smooth and 3 indented seven-wire strands, and 1 smooth and 1 indented three-wire strand) obtained from several different steel manufacturers. A thirteenth wire with chevron indents was later added to verify the findings from the study.

Untensioned pullout tests were conducted on all reinforcements in mortar in the KSU lab. Prisms were also made with all prestressing reinforcements in concrete with different properties, and transfer length was measured upon pretension release for each prism. Then at a tie manufacturing plant, untensioned pullout tests were repeated with 12 wires and 3 strands in concrete, and transfer length was measured on actual concrete crossties made with the same reinforcements at the plant. Key parameters obtained from the untensioned pullout tests, such as maximum pullout force or maximum bond stress up to a certain amount of slip, were correlated with the measured transfer length data. Empirical equations were derived based on these correlations and can be used to predict the transfer length of pretensioned concrete members from untensioned pullout test results. Data from the wire pullout test correlated well with the measured transfer length, and the test was recommended as a standard pullout test method for evaluating the bond quality of $5.32 \mathrm{~mm}$ diameter prestressing wires. The strand pullout test data showed poorer and sometimes 
statistically insignificant correlation with the transfer length, and additional development work was recommended for standardizing the strand pullout test. Detailed test materials and procedures, results and analyses can be found in Arnold et al. (2013) and Bodapati et al. (2013a,b).

Tensioned pullout tests following procedures similar to those specified by Abrishami and Mitchell (1993) were also performed on selected reinforcements. The bond strength data obtained from transfer bond tests on selected wires correlated very well with transfer length. However, the untensioned pullout test is deemed simpler to conduct than the tensioned pullout test (Holste et al., 2013).

Transfer length is calculated based on the surface strain profile of concrete. Traditionally, concrete surface strains have been measured manually using mechanical gauges. In contrast to the traditional method, KSU has developed an automated, non-contact Laser Speckle Image (LSI) technique that measures concrete surface strains rapidly and accurately. KSU has also developed an unbiased statistical method, named Zhao-Lee or ZL method after its authors, that calculates the transfer length based on a given surface strain profile. This contrasts with the traditional $95 \%$ Average Maximum Strain or 95\% AMS method (Russell and Burns, 1993) that has shown bias in its estimation of transfer length. New development combining the LSI technique and the ZL analysis method promises to enable real time, quality control monitoring of the transfer length during large scale in-plant tie production (Zhao et al., 2013a,b).

The test program develops a comprehensive understanding of how various reinforcement and concrete factors contribute to the transfer length of pretensioned concrete ties. This new knowledge can lead to the design of concrete ties with improved performance. Furthermore, the new technology to rapidly measure surface strains and yield transfer lengths can help to detect and replace low quality ties during production. All these will lead to the design, fabrication and placement of consistently high quality concrete ties in track.

In the study presented in this paper, two types of tests were employed to calibrate the FE bond model developed for the smooth prestressing wire: untensioned pullout test and pretensioned concrete prism test. The transfer length data measured on actual concrete crossties made in the plant were further employed to validate the FE bond model. Details of specimen dimensions and measured data from these tests are described in the respective calibration and validation sections.

\section{ELASTOPLASTIC BOND MODELING}

The elastoplastic bond model development follows the general plasticity theory and FE procedure described in Zienkiewicz and Taylor (1991). User subroutines were written for both axisymmetric and 3D cohesive elements in Abaqus, but only the 3D governing equations, similar to the theoretical development for frictional contact by Michalowski and Mroz (1978), are presented here. Figure 1 shows the local coordinate system defined for a 3D cohesive element (Dassault Systèmes, 2012). It includes a normal (or thickness) direction and two shear directions, depicted by unit vectors $\mathbf{n}, \mathbf{s}$ and $\mathbf{t}$, respectively. The traction- 
displacement constitutive relation type is adopted. The interface stress tensor $\sigma$ includes a normal component $\sigma$ and two shear components $\tau_{1}$ and $\tau_{2}$

$$
\boldsymbol{\sigma}=\boldsymbol{\sigma} \mathbf{n}+\tau_{1} \mathbf{s}+\tau_{2} \mathbf{t}
$$

The magnitude of the total shear stress is

$$
|\tau|=\sqrt{\tau_{1}^{2}+\tau_{2}^{2}}
$$

The interface displacement tensor $\mathbf{u}$ includes dilation $u_{\mathrm{n}}$ and slips $u_{\mathrm{t} 1}$ and $u_{\mathrm{t} 2}$

$$
\mathbf{u}=u_{\mathrm{n}} \mathbf{n}+u_{\mathrm{t} 1} \mathbf{s}+u_{\mathrm{t} 2} \mathbf{t}
$$

which can be decomposed into elastic and plastic components

$$
\mathbf{u}=\mathbf{u}^{\mathrm{el}}+\mathbf{u}^{\mathrm{pl}}
$$

The magnitude of the total plastic slip is written as

$$
\left|u_{\mathrm{t}}^{\mathrm{pl}}\right|=\sqrt{\left(u_{\mathrm{t} 1}^{\mathrm{pl}}\right)^{2}+\left(u_{\mathrm{t} 2}^{\mathrm{pl}}\right)^{2}}
$$

Elasticity of the interface material indicates

$$
\boldsymbol{\sigma}=\mathbf{D}^{\mathrm{e}} \mathbf{u}^{\mathrm{el}}=\mathbf{D}^{\mathrm{e}}\left(\mathbf{u}-\mathbf{u}^{\mathrm{pl}}\right)
$$

where $\mathbf{D}^{\mathrm{e}}$ is the elastic matrix with the unit force/length ${ }^{3}$. Assuming decoupled normal-shear behavior, we have $\mathbf{D}^{\mathrm{e}}$ in the following matrix form

$$
\mathbf{D}^{\mathrm{e}}=\left[\begin{array}{ccc}
D_{\mathrm{nn}}^{\mathrm{e}} & 0 & 0 \\
0 & D_{\mathrm{ns}}^{\mathrm{e}} & 0 \\
0 & 0 & D_{\mathrm{nt}}^{\mathrm{e}}
\end{array}\right]
$$

where the normal $\left(D_{\mathrm{nn}}^{\mathrm{e}}\right)$ and shear elastic stiffness $\left(D_{\mathrm{ns}}^{\mathrm{e}}, D_{\mathrm{nt}}^{\mathrm{e}}\right)$ are the only non-trivial components. Isotropy in the shear plane would further imply $D_{\mathrm{ns}}^{\mathrm{e}}=D_{\mathrm{nt}}^{\mathrm{e}}$.

For elastic loading and unloading, the yield function $F$ satisfies $F<0$. When plastic loading occurs, the stress stays on the yield surface:

$$
F=0
$$

The plastic flow can be calculated from the plastic potential $Q$ as follows

$$
\mathrm{d} \mathbf{u}^{\mathrm{pl}}=\mathrm{d} \lambda \frac{\partial Q}{\partial \boldsymbol{\sigma}}
$$

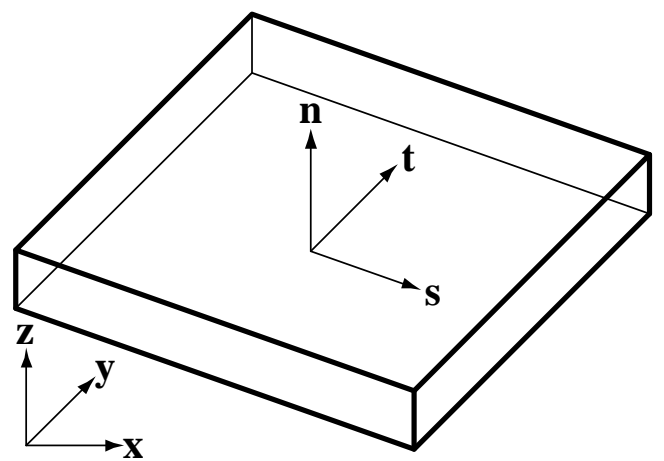

Figure 1. Local coordinate system $(n, s, t)$ for a 3D cohesive element (Dassault Systèmes, 2012). 
where $\mathrm{d} \mathbf{u}^{\mathrm{pl}}$ is the increment of the plastic interface displacement, and $\mathrm{d} \lambda$ is a proportionality constant. Eq. (9) implies an associated flow rule when $Q=F$ and a non-associated flow rule when $Q \neq F$.

For the adhesive and frictional bonding of the smooth prestressing wire with concrete, the yield function can be defined as

$$
F=|\tau|+\sigma \tan \phi-a
$$

where $\phi$ is the friction angle and $\tan \phi$ is the coefficient of friction. Here a form of the adhesive strength $a$ depending linearly on the total plastic slip $\left|u_{\mathrm{t}}^{\mathrm{pl}}\right|$ is chosen

$$
a=\left\{\begin{array}{cl}
a_{0}\left(1-\frac{\left|u_{\mathrm{t}}^{\mathrm{pl}}\right|}{u_{\mathrm{tc}}^{\mathrm{pl}}}\right), & \text { if }\left|u_{\mathrm{t}}^{\mathrm{pl}}\right| \leq u_{\mathrm{tc}}^{\mathrm{pl}} \\
0, & \text { if }\left|u_{\mathrm{t}}^{\mathrm{pl}}\right|>u_{\mathrm{tc}}^{\mathrm{pl}}
\end{array}\right.
$$

where $a_{0}$ is the initial adhesive strength, and $u_{\mathrm{tc}}^{\mathrm{pl}}$ is the plastic slip amount at which adhesion is first broken completely. Figure 2 shows the plot of $a$ as a function of $u_{\mathrm{t}}^{\mathrm{pl}}$. Figure 3 shows the evolution of the yield surface from the initial to the adhesive and then to the frictional stage.

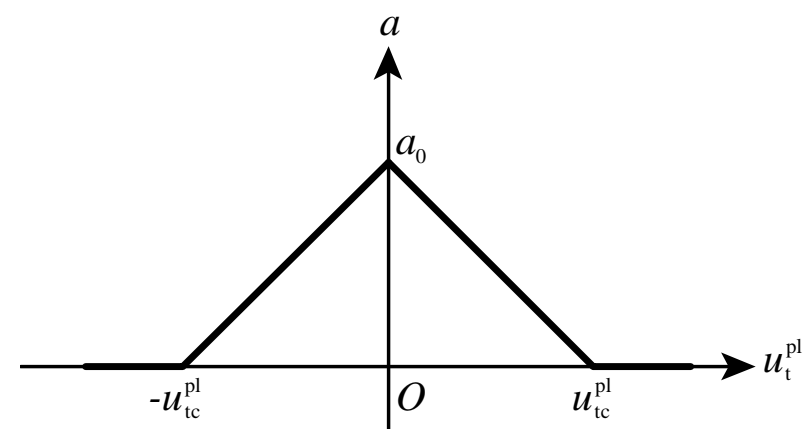

Figure 2. Adhesive strength as a function of plastic slip.

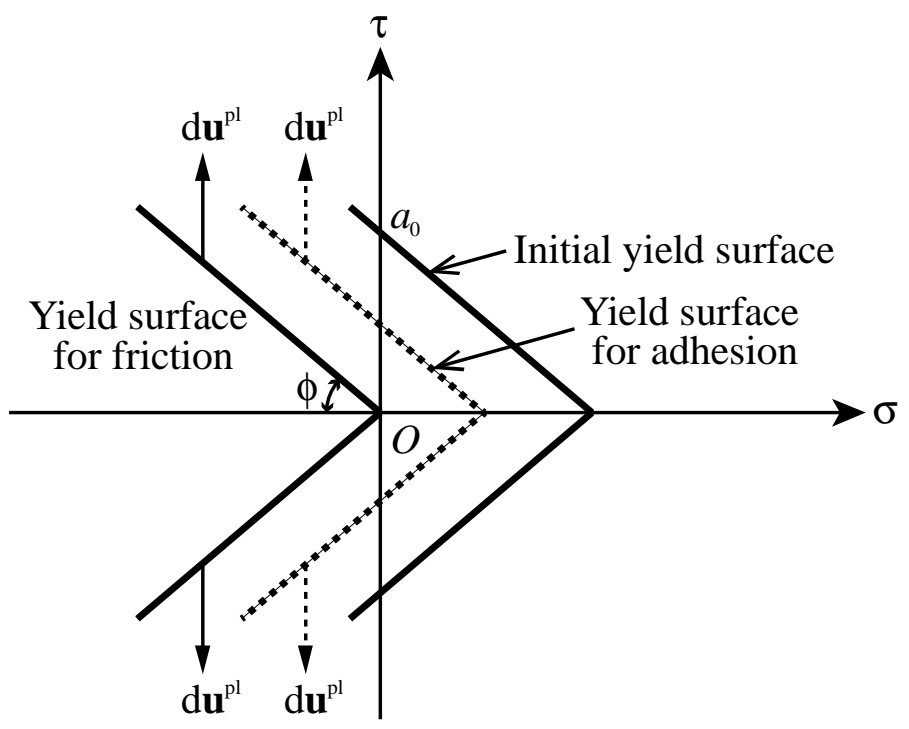

Figure 3. Evolution of yield surface. 
The plastic potential is further defined as

$$
Q=|\tau|
$$

The non-associated plastic flow rule based on Eq. (9) is then written as

$$
\mathrm{d} \mathbf{u}^{\mathrm{pl}}=\mathrm{d} u_{\mathrm{n}}^{\mathrm{pl}} \mathbf{n}+\mathrm{d} u_{\mathrm{t} 1}^{\mathrm{pl}} \mathbf{s}+\mathrm{d} u_{\mathrm{t} 2}^{\mathrm{pl}} \mathbf{t}=\mathrm{d} \lambda \frac{\tau_{1}}{|\tau|} \mathbf{s}+\mathrm{d} \lambda \frac{\tau_{2}}{|\tau|} \mathbf{t}
$$

which implies

$$
\mathrm{d} u_{\mathrm{n}}^{\mathrm{pl}}=0
$$

and

$$
\frac{\mathrm{d} u_{\mathrm{t} 1}^{\mathrm{p}}}{\mathrm{d} u_{\mathrm{t} 2}^{\mathrm{pl}}}=\frac{\tau_{1}}{\tau_{2}}
$$

This means that the plastic flow is aligned with the shear plane and there is no plastic dilation or contraction in the normal direction (see Figure 3). Eqs. $(8,14-15)$

constitute the set of equations to be solved to obtain the stress and displacement state in the adhesive and frictional stages of plastic loading.

In incremental FE analyses, an elastoplastic matrix $\mathbf{D}^{\mathrm{ep}}$, also referred as the user material's Jacobian matrix, is sought to determine the stress increment $\mathrm{d} \sigma$ in terms of the displacement increment du

$$
\mathrm{d} \boldsymbol{\sigma}=\mathbf{D}^{\mathrm{ep}} \mathrm{du}
$$

By enforcing the consistency condition for plastic loading

$$
\mathrm{d} F=\left(\frac{\partial F}{\partial \boldsymbol{\sigma}}\right)^{\mathrm{T}} \mathrm{d} \boldsymbol{\sigma}+\frac{\partial F}{\partial a} \mathrm{~d} a=0
$$

$\mathbf{D}^{\mathrm{ep}}$ can be obtained as follows

$$
\mathbf{D}^{\mathrm{ep}}=\mathbf{D}^{\mathrm{e}}-\frac{\mathbf{D}^{\mathrm{e}} \frac{\partial Q}{\partial \boldsymbol{\sigma}}\left(\frac{\partial F}{\partial \boldsymbol{\sigma}}\right)^{\mathrm{T}} \mathbf{D}^{\mathrm{e}}}{\left(\frac{\partial F}{\partial \boldsymbol{\sigma}}\right)^{\mathrm{T}} \mathbf{D}^{\mathrm{e}} \frac{\partial Q}{\partial \boldsymbol{\sigma}}-\frac{\partial F}{\partial a}\left(\frac{\partial a}{\partial \mathbf{u}^{\mathrm{pl}}}\right)^{\mathrm{T}} \frac{\partial Q}{\partial \boldsymbol{\sigma}}}
$$

Note $\mathbf{D}^{\mathrm{ep}}$ is not symmetric due to the non-associated nature of this interface material. An unsymmetric equation solver should therefore be invoked in the FE program.

\section{BOND MODEL CALIBRATION}

The bond model parameters to be determined are: normal elastic stiffness $D_{\mathrm{nn}}^{\mathrm{e}}$, shear elastic stiffness $D_{\mathrm{ns}}^{\mathrm{e}}\left(=D_{\mathrm{nt}}^{\mathrm{e}}\right)$, initial adhesive strength $a_{0}$, plastic slip $u_{\mathrm{tc}}^{\mathrm{pl}}$ at which adhesion first breaks completely, and coefficient of friction $\tan \phi$. This paper adopted a $\tan \phi$ of 0.45 , close to the average coefficient of friction measured by Baltay and Gjelsvik (1990) between machined mild steel and concrete for normal stresses between 1 and 68,000 psi. The untensioned pullout test and pretensioned concrete prism test data provided by KSU were used to calibrate the rest of the model parameters. Figure 4 shows the dimensions of the specimens used in the two tests. 


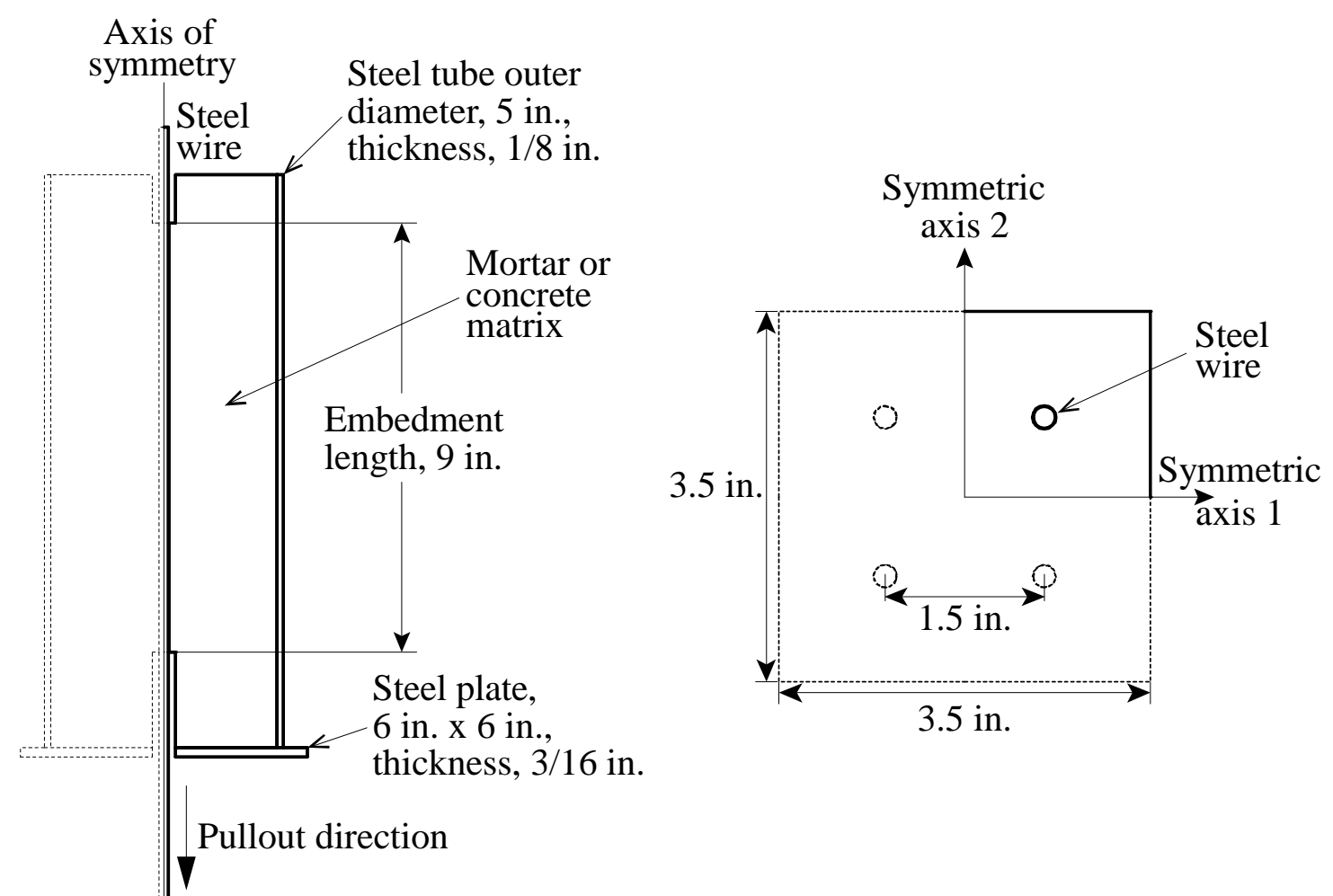

Figure 4. Un-tensioned wire pullout test (left) and cross section of pretensioned concrete prism (right): dimensions and assumed symmetry in FE modeling.

It is noted that the untensioned wire pullout test shown here used a preliminary setup that differed from the final recommended version. The pullout test was conducted in both mortar and concrete, and the displacement at the unloaded end of the steel wire and the pullout force were recorded. Axisymmetry was assumed so only one longitudinal section was modeled for the pullout test.

The cross section of a concrete prism was assumed to be quarter symmetric as shown in Figure 4. Further, the prisms measured 69 in. in length, and symmetry was also assumed along this dimension about the center section. As a result, only oneeighth of a prism was constructed in FE modeling. The wires in the concrete prisms were pretensioned to 7,000 pound force, equivalent to an initial tensile stress of over 203,000 psi. Once the concrete reached a desired compressive strength, the pretension was released by cutting the wires at the prism ends. Concrete surface strains were then measured for each prism and used to calculate the transfer length.

The prism tests were conducted at three nominal compressive strengths $\left(f_{\mathrm{c}}\right)$ at release for concrete: 3500,4500 and 6000 psi. The untensioned pullout tests were conducted at $f_{\mathrm{c}}=4500 \mathrm{psi}$ for mortar or concrete. Table 1 summarizes the basic measured material properties (Young's modulus $E$, tensile strength $\sigma_{\mathrm{t} 0}$ and compressive strength $\sigma_{\mathrm{cu}}$ ) averaged over available data sets. Steel parameters (Young's modulus $E$ and yield strength $\sigma_{\mathrm{Y}}$ ) for the smooth prestressing wire were provided by the manufacturer. Additional material parameters required in the damaged plasticity modeling of concrete were derived from the basic material parameters and the equations outlined in Yu et al. (2011) and Yu and Jeong (2012). Static FE analyses of the wire pullout and prism tests were conducted. Simulation 
results of pullout force vs. unloaded wire end displacement and compressive strain on the concrete prism surface were compared with the corresponding experimental data. Bond parameters were calibrated via an iterative process that involved FE simulation, comparison of simulation results versus test data, and adjustment of model parameters until reasonably good agreement was achieved between test and simulation data for both tests. It was observed that the shear elastic stiffness mainly affected the wire pullout simulation results, the normal elastic stiffness mainly affected the prism simulation results, and the adhesion parameters affected both simulation results.

Table 1. Average measured or manufacturer provided material parameters

\begin{tabular}{|c|c|c|c|c|c|c|}
\hline \multirow[b]{2}{*}{ Nominal $f_{\mathrm{c}}$ (psi) } & \multirow{2}{*}{$\begin{array}{r}\text { Mortar } \\
4,500\end{array}$} & \multicolumn{3}{|c|}{ Concrete } & \multirow{2}{*}{\multicolumn{2}{|c|}{ Steel }} \\
\hline & & 3,500 & 4,500 & 6,000 & & \\
\hline$E$ (ksi) & 3,340 & 3,259 & 3,655 & 4,028 & $E(\mathrm{ksi})$ & 30,000 \\
\hline$\sigma_{\mathrm{t} 0}(\mathrm{psi})$ & 413.9 & 366.0 & 439.4 & 478.8 & $\sigma_{\mathrm{Y}}(\mathrm{psi})$ & 274,000 \\
\hline$\sigma_{\mathrm{cu}}(\mathrm{psi})$ & 4661.5 & 3586.0 & 4570.2 & 5977.8 & & \\
\hline
\end{tabular}

The final calibrated parameters for the bond between steel and concrete are presented in Table 2. They apparently depend on the nominal compressive strength $f_{\mathrm{c}}$ of concrete. The bond parameters for the steel-mortar interface were not calibrated owing to insufficient data. Figure 5 shows the pullout force-unloaded end displacement curves compared between test and simulation for the wire pullout in concrete. The individual test curves and their average are shown. The curves from the pullout test in mortar are also shown. Figure 5 indicates that using data from the pullout test in mortar to calibrate the steel-concrete interface properties would have underestimated the shear bonding parameters.

Table 2. Calibrated bond model parameters

\begin{tabular}{|c|c|c|c|}
\hline \multirow[b]{2}{*}{ Nominal $f_{\mathrm{c}}(\mathrm{psi})$} & \multicolumn{3}{|c|}{ Concrete } \\
\hline & 3,500 & 4,500 & 6,000 \\
\hline$D_{\mathrm{nn}}^{\mathrm{e}}\left(\mathrm{lbf} / \mathrm{in}^{3}\right)$ & $7,170,252$ & $10,233,482$ & $12,889,494$ \\
\hline$D_{\mathrm{ns}}^{\mathrm{e}}\left(\mathrm{lbf} / \mathrm{in}^{3}\right)$ & 149,380 & 213,198 & 268,531 \\
\hline$a_{0}(\mathrm{psi})$ & 205 & 230 & 253 \\
\hline$u_{\mathrm{tc}}^{\mathrm{pl}}($ in $)$ & 0.062 & 0.070 & 0.077 \\
\hline
\end{tabular}

Figure 6 compares the concrete surface strain profiles predicted by FE modeling versus those measured in the prism tests. There were up to six measurements for each wire, and their average is shown in Figure 6. At all concrete release strength levels, the measured strains are consistently higher than those predicted by modeling. It was reported that for logistic reasons, concrete strains could not be measured at the same time the wire pretension was released, and the time lapse between the two events led to considerable concrete creep by the time of strain measurement. A method to account for the added strains due to creep was therefore needed to make meaningful comparisons between the test data and the simulation results on strains. 


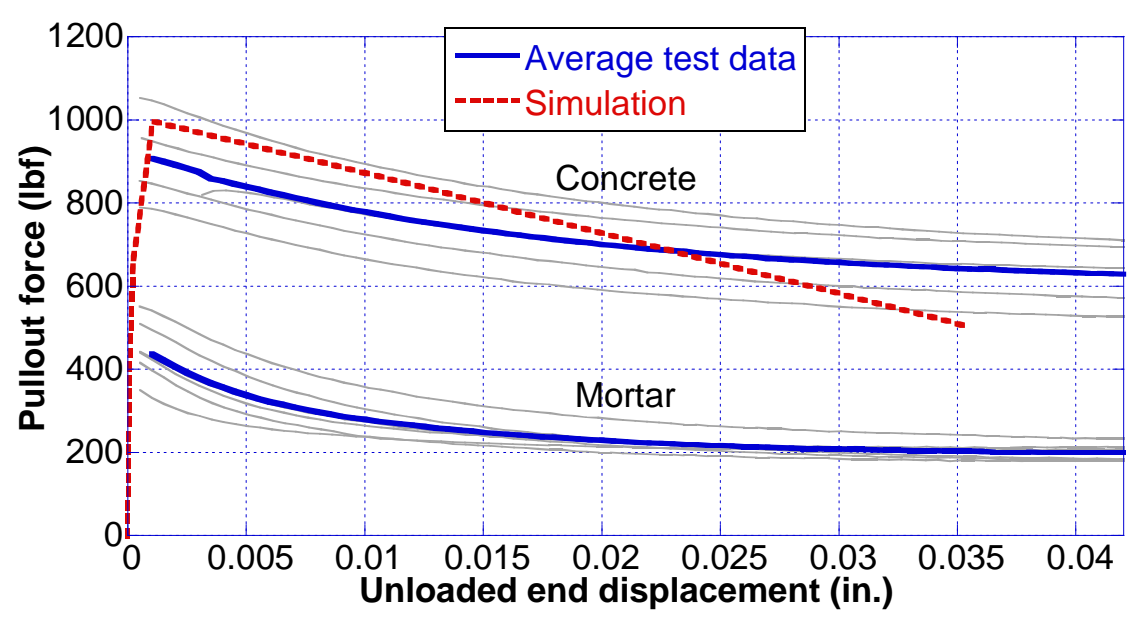

Figure 5. Pullout force-unloaded end displacement curves: test vs. simulation for wire pullout in concrete, and test curves for wire pullout in mortar.

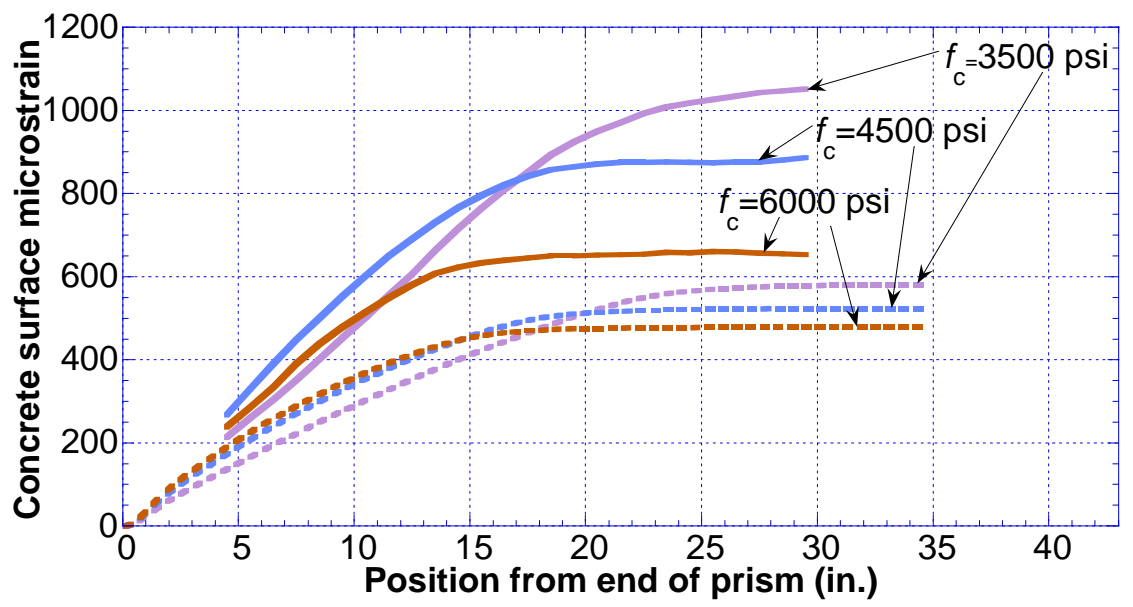

Figure 6. Measured (solid lines) vs. model predicted surface strain profiles (dotted lines) in concrete prisms: without creep adjustment.

Bazant and Baweja (2000) postulated that for a constant uniaxial stress $\sigma$ within the service range that is applied at age $t^{\prime}$, the strain $\varepsilon$ at age $t$ can be written as

$$
\varepsilon(t)=J\left(t, t^{\prime}\right) \sigma+\varepsilon_{\mathrm{sh}}(t)+\alpha \Delta T(t)
$$

where $J$ is the compliance function, $\varepsilon_{\text {sh }}$ is the shrinkage strain, $\alpha$ is the thermal expansion coefficient, and $\Delta T$ is the temperature change. The compliance function can be further expressed in elastic and creep terms as

$$
J\left(t, t^{\prime}\right)=1 / E\left(t^{\prime}\right)+C_{0}\left(t, t^{\prime}\right)+C_{\mathrm{d}}\left(t, t^{\prime}, t_{0}\right)
$$

where $E\left(t^{\prime}\right)$ is the modulus of elasticity at loading age $t^{\prime}, C_{0}\left(t, t^{\prime}\right)$ is the basic creep compliance, and $C_{\mathrm{d}}\left(t, t^{\prime}, t_{0}\right)$ is the creep compliance due to simultaneous drying. Assuming only the basic creep mechanism is in effect here, we rewrite Eq. (19) as

$$
\varepsilon(t)=\sigma / E\left(t^{\prime}\right)+\sigma C_{0}\left(t, t^{\prime}\right)
$$

In pretensioned concrete members, usually the compressive stress in the longitudinal direction along which the pretensions are applied is the only predominant 
stress component, so the stress state is approximately uniaxial meaning Eq. (21) can be applied directly. The measured total strains contain both elastic and creep components, but they are not readily distinguished in Eq. (21) because of the two unknowns: $\sigma$ and $C_{0}$. On the other hand, both strain and stress states can be obtained from FE analyses. By applying the FE stress, FE elastic strain and measured total strain in Eq. (21), the creep compliance $C_{0}$ can be estimated and used to calculate the creep strain, which can then be added to the FE predicted surface strain, making the latter more comparable to the test data.

If we designate the measured strain at a selected location on the prism as $\varepsilon_{\text {test }}$ and the FE predicted strain at the same location as $\varepsilon_{\mathrm{FE}}$, Eq. (21) may be rewritten as

$$
\varepsilon_{\text {test }}=\varepsilon_{\mathrm{FE}}+\varepsilon_{\mathrm{FE}} E C_{0}
$$

where it is assumed that the FE predicted stress $\sigma_{\mathrm{FE}}=\varepsilon_{\mathrm{FE}} E$. Solving Eq. (22) yields

$$
C_{0}=\frac{\varepsilon_{\mathrm{test}}-\varepsilon_{\mathrm{FE}}}{\varepsilon_{\mathrm{FE}} E}
$$

Usually the strains used in Eq. (23) were taken where the maximum or average maximum occurred. The FE predicted strain can then be adjusted as follows

$$
\varepsilon_{\mathrm{FE}+\text { creep }}=\varepsilon_{\mathrm{FE}}+\sigma_{\mathrm{FE}} C_{0}
$$

The parameter $C_{0}$ was involved in the iterative calibration process via Eqs. $(23,24)$. The $C_{0}$ 's so obtained were $0.249,0.190$ and 0.095 microstrain/psi, respectively, for $f_{\mathrm{c}}=3500,4500$ and 6000 psi.

Figure 7 compares the FE predicted surface strain profiles, with adjustment based on Eqs. $(23,24)$, versus the test data. Figure 8 compares the calculated transfer lengths from the surface strain data using 95\% AMS method (Russell and Burns, 1993) or ZL method (Zhao et al., 2013b). The simulation results show good agreement with the corresponding test data. Both test and simulation data indicate that the transfer length decreases with an increase in the release strength of concrete.

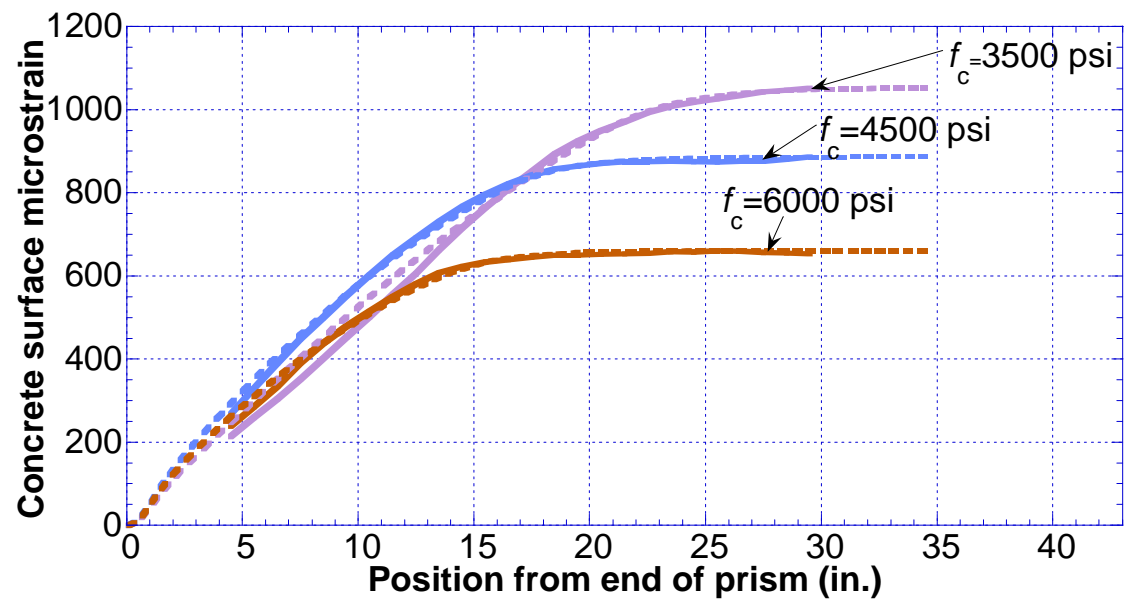

Figure 7. Measured (solid lines) vs. model predicted surface strain profiles (dotted lines) in concrete prisms: with creep adjustment. 


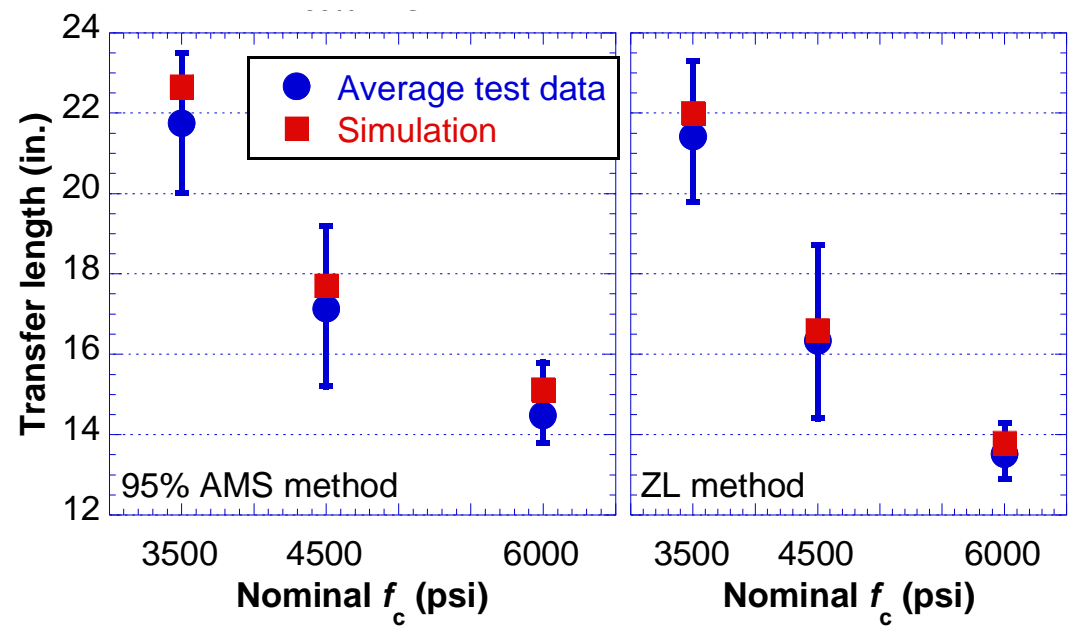

Figure 8. Transfer lengths calculated for concrete prisms using 95\% AMS method or ZL method: test (minimum, average and maximum) vs. simulation.

\section{VALIDATION}

The concrete crossties made at the plant had 20 prestressing wires. Figure 9 shows the end and symmetric side views of the geometric model of the tie. Compared to the pretensioned prisms tested in the lab, the ties are nonprismatic, and there are several scallops along the sides of the tie. The same concrete mix and wire pretension as those in the lab phase were used. The concrete release strength was $f_{\mathrm{c}}=5365$ psi for the tie with the smooth wire (Bodapati et al., 2013b). Quarter symmetric tie models were developed, with which the pretension release process was simulated. The concrete material parameters and calibrated bond model parameters corresponding to both $f_{\mathrm{c}}=4500$ and 6000 psi were applied in the simulations.

Figure 10 compares the concrete surface strains measured using the LSI technique to those obtained in the simulation using parameters for $f_{\mathrm{c}}=6000 \mathrm{psi}$. The surface strains were measured at the bottom of the tie. The gray lines are individual measurements and show larger scattering than the lab results. There were many more measurements made at the plant (over 40) than in the lab (up to 6) for each wire. It is conceivable that the longer time it took to complete all the measurements at the plant gradually added more creep strains to the total strains, and thus the strain variations over time were larger than normal experimental scattering. The average test curve is also plotted. The simulation curve without creep adjustment shows generally lower strains than any test curves. After creep strain adjustment with a creep compliance of $C_{0}=0.138 \mathrm{microstrain} / \mathrm{psi}$, the simulation curve agrees well with the average test curve not only in magnitudes but also in the general curve shape.
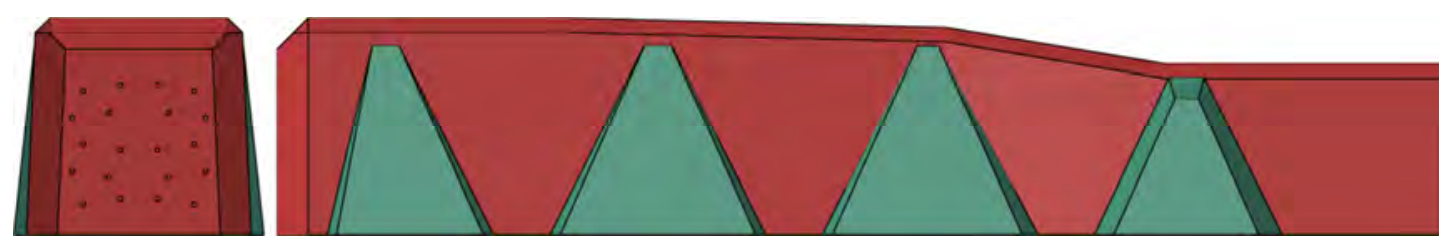

Figure 9. End and symmetric side views of the concrete crosstie model. 
It is observed that the strain profiles of prismatic concrete members generally include an ascending branch followed by a plateau (see Figures $6 \& 7$ ), whereas the strain profiles of non-prismatic concrete ties with scallops include an ascending branch followed by local peaks and troughs (see Figure 10). FE analyses attributed the latter mainly to the presence of the scallops. Zhao et al. (2013c) generalized the ZL method to accommodate this type of strain profiles used in the transfer length calculation and discussed the fundamental question of how transfer lengths may be defined and mathematically determined.

Figure 11compares the calculated transfer lengths for the ties obtained from tests versus simulations. The simulation results using parameters for $f_{\mathrm{c}}=6000 \mathrm{psi}$ agree very well with the average test data. The simulation results using parameters for $f_{\mathrm{c}}=4500 \mathrm{psi}$ are higher than the average but also within the range of the test data. The actual release strength of 5365 psi is closer to $f_{\mathrm{c}}=6000 \mathrm{psi}$, so the simulation with $f_{\mathrm{c}}=6000$ psi was considered a better approximation .

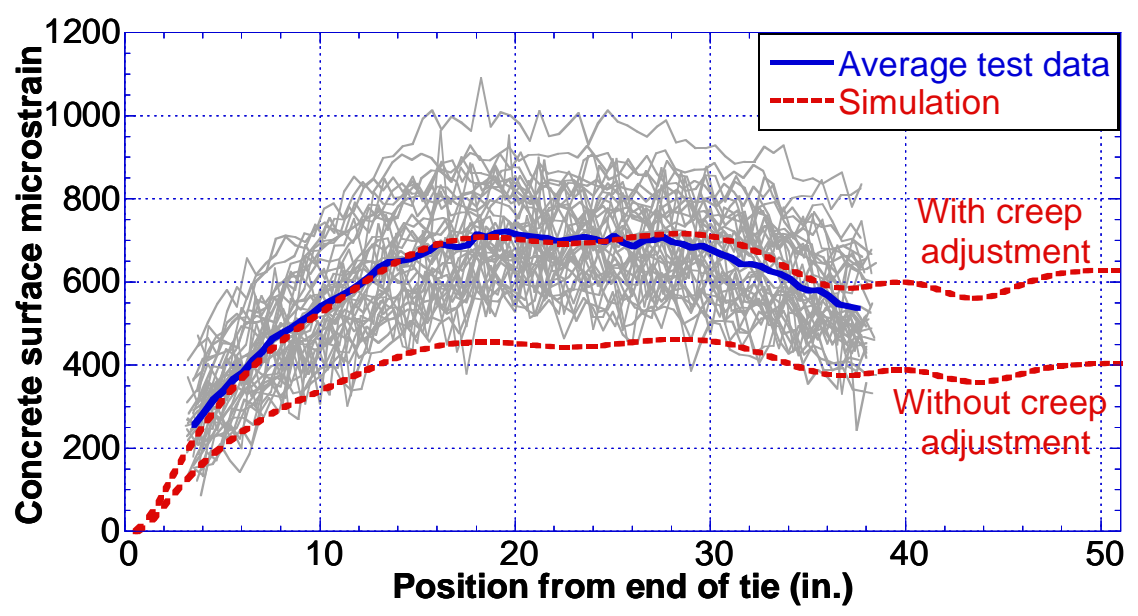

Figure 10. Measured (solid lines) vs. model predicted surface strain profiles (dotted lines, using model parameters corresponding to $f_{\mathrm{c}}=6000 \mathrm{psi}$ ) in concrete crossties.

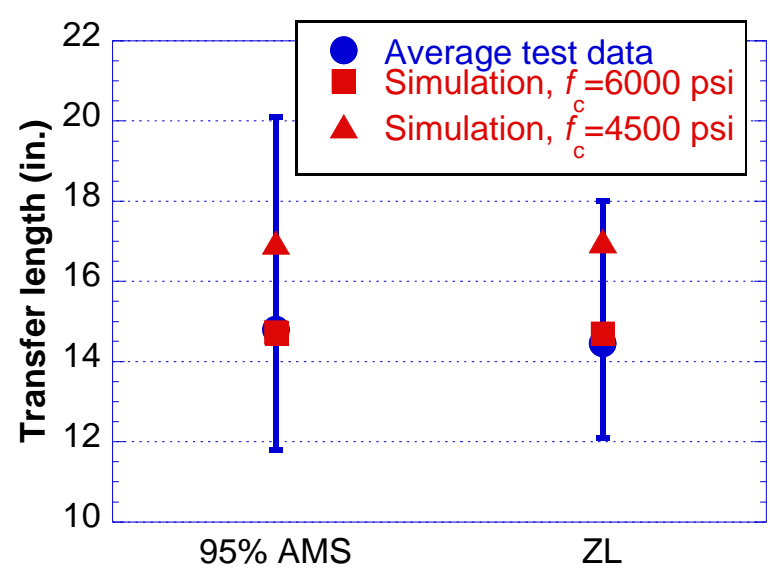

Figure 11. Transfer lengths calculated for concrete crossties using 95\% AMS method or ZL method: test (minimum, average and maximum) vs. simulation. 


\section{CONCLUSIONS AND FUTURE WORK}

An elastoplastic bond model was developed for the interface between the smooth prestressing wire and concrete in the railroad concrete tie application. The bond model with parameters calibrated from laboratory wire pullout and pretensioned prism tests made satisfactory predictions of surface strains and transfer lengths in the pretensioned concrete crossties made at a plant. The main bond model parameters for elasticity and adhesion exhibited a dependence on the concrete release strength. Both the test results and the FE analyses indicated that the transfer length decreased with increased release strength of concrete. A creep strain adjustment to the FE predicted strain profiles was necessary to account for the concrete creeping mechanism observed in the tests but not directly simulated in modeling. Such creep strain adjustment was based on combined test and simulation data.

Future work will include elastoplastic bond modeling of indented prestressing wires and strands whose dominant bonding mechanisms with concrete also include mechanical interaction. The mechanical interaction of reinforcement indents with concrete is believed to introduce normal (or radial) dilations of the interface that can split the concrete. The elastoplastic bond modeling method presented in this paper appears well-suited for the phenomenological modeling of this type of behavior.

\section{ACKNOWLEDGEMENT}

The work described in this paper was sponsored by the Office of Research and Development, Federal Railroad Administration, U.S. Department of Transportation, under the direction of Mr. Gary Carr, Chief of the Track Research Division. The authors are grateful to Professor Robert J. Peterman, Professor B. Terry Beck and their research team at Kansas State University for sharing the test data applied in this study and for their many insightful presentations and discussions.

\section{REFERENCES}

Abrishami, H., and Mitchell, D. (1993). "Bond characteristics of pretensioned strand." ACI Materials Journal, 90(3), 228-235.

Arnold, M. L., Peterman, R. J., Bodapati, N. N. B., Beck, B. T., and Wu, C. H. J. (2013). "Development of a standard bond test for indented prestressing wires." Proc. 2013 Joint Rail Conference, JRC2013-2461.

Baltay, P., and Gjelsvik, A. (1990). "Coefficient of friction for steel on concrete at high normal stress." J. Mater. Civ. Eng., 2(1), 46-49.

Bazant, Z. P., and Baweja, S. (2000). "Creep and shrinkage prediction model for analysis and design of concrete structures: Model B3." ACI Special Publications, 194, 1-84.

Bodapati, N. N. B., Zhao, W., Peterman, R. J., Wu, C. H. J., Beck, B. T., Haynes, M., and Holste, J. R. (2013a). "Influence of indented wire geometry and concrete parameters on the transfer length in pretensioned concrete crossties." Proc. 2013 Joint Rail Conference, JRC2013-2463. 
Bodapati, N. N. B., Peterman, R. J., Zhao, W., Beck, B. T., Wu, C. H. J., Holste, J. R., Arnold, M. L., Benteman, R., and Schweiger, R. (2013b). "Transfer-length measurements on concrete railroad ties fabricated with 15 different prestressing reinforcements." Proc.2013 PCI Convention and National Bridge Conference.

Cox, J. V., and Herrmann, L. R. (1998). "Development of a plasticity bond model for steel reinforcement." Mechanics of Cohesive - frictional Materials, 3(2), 155180.

Dassault Systèmes (2012). Abaqus analysis user's manual.

Hanna, A. N. (1979). "State-of-the-art report on prestressed concrete ties for North American railroads." PCI Journal, September-October, 32-61.

Holste, J. R., Peterman, R. J., Bodapati, N. N. B., Beck, B. T., and Wu, C. H. J. (2013). "Transfer bond test used to predict transfer length of concrete railroad tie.” Proc. ASME 2013 Rail Transportation Division Fall Technical Conference, RTDF2013-4726.

Michalowski, R., and Mroz, Z. (1978). "Associated and non-associated sliding rules in contact friction problems." Archives of Mech., 30(3), 259-276.

Russell, B. W., and Burns, N. H. (1993). "Design guidelines for transfer, development and debonding of large-diameter seven-wire strands in pretensioned concrete girders." Report No. 1210-5F, Center for Transportation Research, the University of Texas at Austin.

Van Dyk, B. J., Dersch, M. S., and Edwards, J. R. (2012). "International concrete crosstie and fastening system survey - final results." Report submitted to Federal Railroad Administration.

Yu, H., Jeong, D. Y., Choros, J., and Sussmann, T. (2011). "Finite element modeling of prestressed concrete crossties with ballast and subgrade support." Proc. ASME 2011 International Design Engineering Technical Conferences \& Computers and Information in Engineering Conference, DETC2011-47452.

$\mathrm{Yu}, \mathrm{H}$., and Jeong, D. Y. (2012). "Railroad tie responses to directly applied rail seat loading in ballasted tracks: a computational study." Proc. ASME/ASCE/IEEE 2012 Joint Rail Conference, JRC2012-74149.

ZETA-TECH (2010). "Assessment of concrete tie life on U.S. freight railroads." Railway Tie Association Tie Report \#12.

Zhao, W., Beck, B. T., Peterman, R. J., and Wu, C. H. J. (2013a). "Development of a 5-camera transfer length measurement system for real-time monitoring of railroad crosstie production." Proc. 2013 Joint Rail Conference, JRC20132468.

Zhao, W., Beck, B. T., Peterman, R. J., Murphy, R., Wu, C. H. J., and Lee, G. (2013b). "A direct comparison of the traditional method and a new approach in determining 220 transfer lengths in prestressed concrete railroad ties." Proc. 2013 Joint Rail Conference, JRC2013-2469.

Zhao, W., Beck, B. T., Peterman, R. J., Wu, C. H. J., Lee, G., and Bodapati, N. N. B. (2013c). "Determining transfer length in pre-tensioned concrete railroad ties: is a new evaluation method needed?" Proc. ASME 2013 Rail Transportation Division Fall Technical Conference, RTDF2013- 4727. 
Zienkiewicz, O. C., and Taylor, R. L. (1991). The finite element method Vol. 2 Solid and fluid mechanics Dynamics and non-linearity, Fourth edition, McGrawHill, London. 